\title{
Detection of single amino acid differences in haemoglobin from blood samples using a nanopore
}

Gang Huang, Roderick Corstiaan Abraham Versloot, and Giovanni Maglia*

Groningen Biomolecular Sciences \& Biotechnology Institute, University of Groningen, 9747 AG Groningen, The Netherlands

*Corresponding author: g.maglia@rug.nl

\begin{abstract}
The real-time identification of protein biomarkers is under intense investigation for the development of point-of-care and portable devices. Here we use a PlyAB biological nanopore to detect a range of folded Haemoglobin $(\mathrm{Hb})$ variants in blood samples. Blockades of $\mathrm{HbA}$ and sickle cell anaemia $\mathrm{HbS}$, which differ by just one amino acid, and fetal $\mathrm{HbF}$ were distinguished with more than $97 \%$ accuracy on the basis of individual events. This nanopore approach is quick and straightforward. It can count and confirm the identity of $\mathrm{Hb}$ variants instantaneously directly from blood samples. Therefore, PlyAB nanopores are promising single-molecule nanoreactors for real-time folded protein analysis, and identification with immediate application in point-of-care $\mathrm{Hb}$ counting and sickle cell anaemia diagnosis.
\end{abstract}


The ability of measuring biological molecules in real-time or with minimal sample preparation at the point-of-care (POC) would save lives and reduce the cost of healthcare. Measurement of the haemoglobin concentration is a routine blood tests ${ }^{[1]}$, and is especially important for the patient with anaemia diseases ${ }^{[2]}$. Blood samples are usually sent to hospital laboratories where the several tests are used to measure the concentration of haemoglobin $(\mathrm{Hb})^{[3],[4],[5]}$. In more complex tests where different haemoglobin variants must be distinguished, for instance the haemoglobin in normal people (haemoglobin $\mathrm{A}, \mathrm{HbA}$ ) and in the sickle cell anaemia patient (haemoglobin $\mathrm{S}, \mathrm{HbS}$ ), agarose or cellulose electrophoresis is performed to separate the variants based on their charge difference ${ }^{[6,7]}$. But for the quantification of the variants, which could spontaneously co-exist in heterozygote (A/S) type patient, high performance liquid chromatography (HPLC) or capillary electrophoresis (CE) is needed ${ }^{[8,9]}$. Although these techniques are common in a laboratory, they provide a slow answer and they require a laboratory operated by trained personnel. As POC and personalized medicine is gaining momentum ${ }^{[10,11]}$, the development of portable and low-cost device for the quick detection and quantification of haemoglobin variants and other protein becomes important.

Ionic currents through nanopores are emerging as a powerful single-molecule tool for biomacromolecule sensing, ${ }^{[12,13]}$ and have been implemented in low cost portable devices for DNA sequencing ${ }^{[14-17]}$ More recently, nanopores have also been utilized for the detection and analysis of proteins. Solid-state nanopores ${ }^{[18,19]}$ measured the size and shape of chemically modified proteins anchored to the nanopore ${ }^{[20,21]}$, ubiquitination modifications ${ }^{[22]}$, and the conformational flexibility of proteins translocating nanopores. ${ }^{[23,24]}$ Biological nanopores generally perform better as sensors compared their solid-state counterparts. However, they mostly consist of 1-2 nm diameter nanopores, and folded proteins were mainly detected by attaching binding element at the entrance of nanopore. ${ }^{[25-30]}$ Although the identification of protein modifications, such as glycosylation was observed, ${ }^{[28,29]}$ it is to be shown these sensors will be capable to identify small difference such as point mutations in bound proteins. Nanopores with a larger diameter such as cytolysin $A(C l y A)^{[31,32]}$ and Fragaceatoxin $C$ $(\mathrm{FraC})^{[33-35]}$ were recently introduced that can sample proteins up to $\sim 40 \mathrm{kDa}$ lodged inside the nanopore lumen. ${ }^{[36-41]}$ And large post-translational modifications such as ubiquitination have been identified. ${ }^{[42]}$

Here, we show that the two components (pleurotolysin ${ }^{[43]}$, PlyAB-E1 ${ }^{[44]}$ ) nanopore, which has a large $\beta$-barrel cylindrical shape (Fig. 1a) can discriminate $\mathrm{HbA}, \mathrm{HbS}$ and $\mathrm{HbF}$ (64.5 kDa). We show that $\mathrm{HbA}$ and $\mathrm{HbS}$, differing by just one amino acid, produce a significantly different nanopore signal, allowing an accurate detection of $\mathrm{Hb}$ varians. In addition, we show that PlyAB nanopore can detect haemoglobin directly from disrupted red blood cells. Hence, 
PlyAB nanopores provide a new sensor for real-time detection and identification of folded proteins.

$\mathrm{HbA}$ represents the most abundant haemoglobin in healthy people (over $95 \%$ of the total haemoglobin). $\mathrm{HbS}$, which contains a single valine to glutamate acid substitution in the position 6 of $\beta$ chain subunits (Fig. 1), provokes sickle cell anaemia. Here, we added haemoglobin to the trans side of PlyAB-E1 nanopores in a $300 \mathrm{mM} \mathrm{NaCl}$ solution and $\mathrm{pH} 7.5$. PlyAB-E1 is an engineered variant of PlyAB that was selected for its higher solubility during nanopore preparation ${ }^{[44]}$. Under positive applied potentials (e.g. $+50 \mathrm{mV}$ ) both $\mathrm{HbA}$ and $\mathrm{HbS}$ added to the trans side of PlyAB elicited well defined blockades (Fig. 1b,c), while at negative potentials (trans) no capture events were observed (Fig. S1). The inner surface of PlyAB-E1 is negatively charged, which makes the nanopore slightly cation selective and generates a strong electroosmotic flow (EOF) from trans to cis under positive applied potentials ${ }^{[44]}$. The blockades elicited by $\mathrm{HbA}$ and $\mathrm{HbS}$ both gave two distinguished levels, a deeper level (level 1) and an upper level (level 2, Fig. 1b). HbA lodged mainly in the upper level 2 (fractional occupancy of L2 $=0.658 \pm 0.056$ ), while $\mathrm{HbS}$ showed the opposite behaviour (fractional occupancy of $L 2=0.379 \pm 0.04$, Fig. 1c). The blockades switched from level 2 to level 1 every $1.7 \pm 0.5 \mathrm{~ms}$ for $\mathrm{HbA}$ and $0.8 \pm 0.2 \mathrm{~ms}$ for $\mathrm{HbS}$. 
a

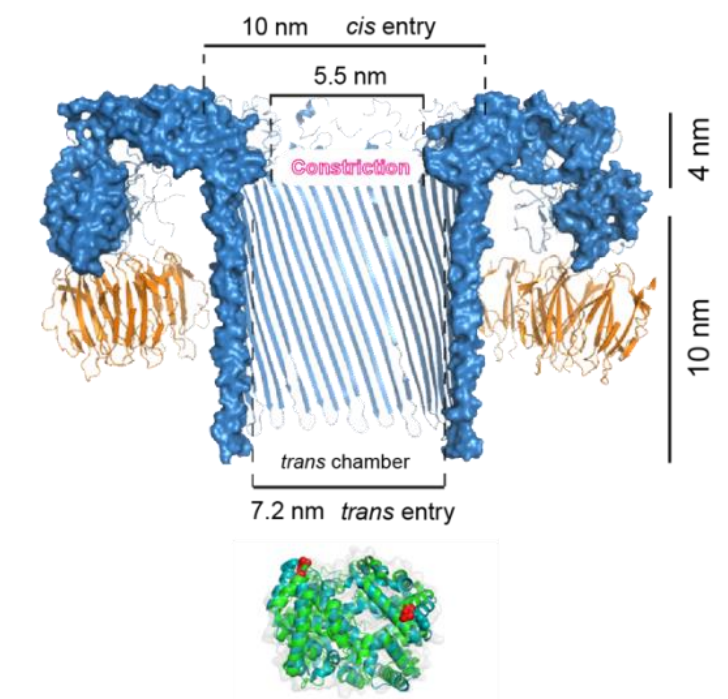

Hemoglobin A (Hemo A): ***VHLTPEEKSAVTALWGKVNVDEVGGEA*** Hemoglobin S (Hemo S): ***VHLTPVEKSAVTALWGKVNVDEVGGEA***

b $\mathrm{HbA}$
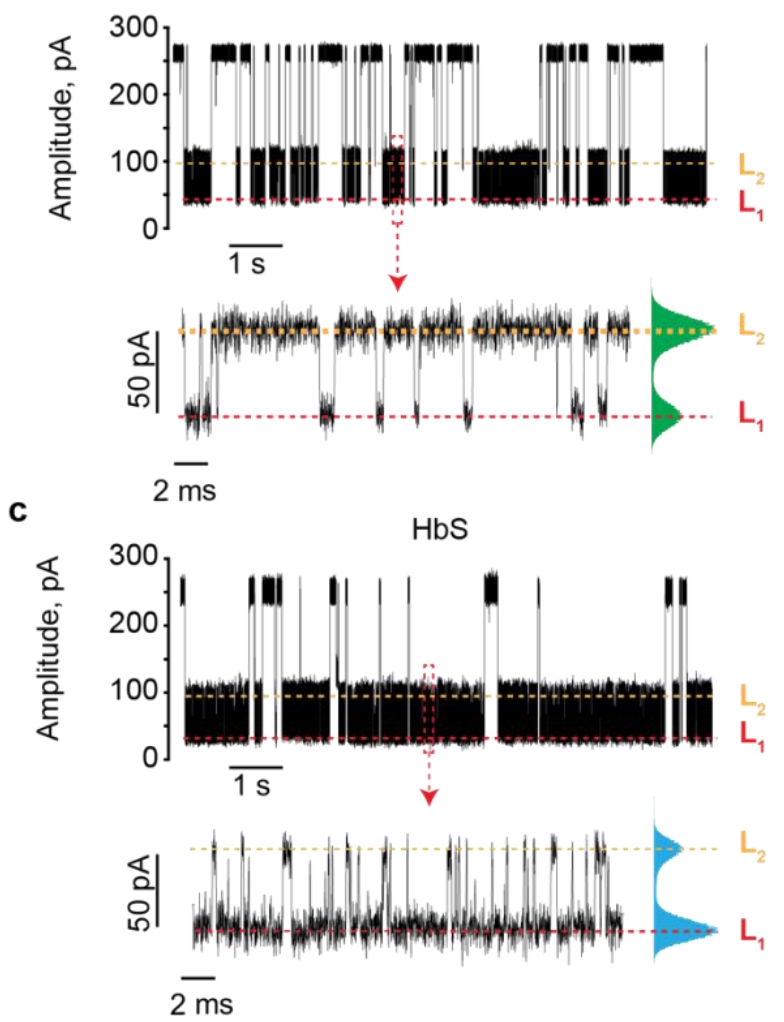

Figure 1. $\mathrm{HbA}$ and $\mathrm{S}$ blockades to PlyAB nanopores. (a) Top, cut through of a cartoon representation of PlyAB nanopore ${ }^{[43]}$. PlyA is in orange and PlyB in blue. Bottom, alignment of deoxy-human haemoglobin $\mathrm{A}$ ( $\mathrm{HbA}$, PDB: $1 \mathrm{GZX})$ and sickle cell disease haemoglobin $\mathrm{S}(\mathrm{HbS}$, PDB: 5E83). b and c, typical $\mathrm{HbA}$ (b) and $\mathrm{HbS}$ (c) blockades to PlyAB nanopores. In the enlarged trace, the deeper level is assigned to level 1 (L1, red) and the upper level to level 2 (L2, orange). A whole trace histogram is shown on the side of the blockade. $\mathrm{Hb}(155 \mathrm{nM})$ is added to the trans side. The recordings were performed in $300 \mathrm{mM} \mathrm{NaCl}$ with a $50 \mathrm{KHz}$ sampling rate and $10 \mathrm{kHz}$ low-pass Bessel filter and the potential clamped to $+50 \mathrm{mV}$. 
Most likely, the two blockades represent the lodging of the haemoglobin molecules in two different residence sites inside the nanopore, as previously observed for thrombin in ClyA nanopores ${ }^{[32]}$. The relative distribution of $L 1$ increased with the voltage for both haemoglobin types suggesting that $\mathrm{L} 1$ represents the $\mathrm{Hb}$ when it occupies the binding site deeper within the pore. Interestingly, the values of Ires\% - the ratio percent between the current of the blocked pore $\mathrm{I}_{\mathrm{B}}$ and the open pore current $\left(\mathrm{I}_{\mathrm{O}}\right)$ - for L1 remained constant over the applied potential (Fig. S2, Table S3), suggesting that the L1 binding site is at a steric minimum near the constriction of the nanopore. In contrast, the Ires\% of L2 decreased with the applied potential (Table S1,2) suggesting that higher potentials draw the protein within the nanopore lumen towards the PlyAB-E1 constriction (Fig. 1). The overall dwell time of $\mathrm{HbA}$ and $\mathrm{HbS}$ blockades reached a maximum at $+50 \mathrm{mV}$ and decreased upon the further increase of voltages (Fig. S3, Table S4), reflecting the translocation of haemoglobin molecules under high potentials. We also found that the fractional occupancy (Fig. S5c, Table S5) and the Ires\% (Fig. S5d, Table S6) of level 2 for both $\mathrm{HbA}$ and $\mathrm{HbS}$ increased with the $\mathrm{pH}$, while the dwell time of haemoglobin decreased (Fig. S4, Table S7). Such dependences are likely to reflect the effect of the overall charges of $\mathrm{HbA}$ and $\mathrm{HbS}$. At positive applied potentials there is a strong electroosmotic force (EOF) from trans to cis that pushes proteins inside the nanopore ${ }^{[44]}$. This is counterbalanced by the electrophoretic force (EPF) that pushes the negatively charged $\mathrm{HbA}\left(\mathrm{pl}=7.1^{[45]}\right)$ and $\mathrm{HbS}\left(\mathrm{pl}=7.3^{[45]}\right)$ in the opposite direction. At higher $\mathrm{pH}$, haemoglobin becomes more negatively charged, causing a strong opposite EPF that prevents the capture of haemoglobin into the PlyAB-E1 nanopores and reduces the dwell time. Interestingly, the sigmoidal $\mathrm{pH}$ dependence observed for L2 occupancy showed an inversion point at $\mathrm{pH} 8.0$ for both haemoglobin proteins (Fig. S5c), which might reflect the protonation of one or more cysteine residues (pka $=8$ ) in haemoglobin.

A precise haemoglobin quantification of both $\mathrm{HbA}$ and $\mathrm{HbS}$ at the single blockade level is important, because both coexist in the blood of heterozygote (A/S) type sickle cell anaemia patients. We identified two parameters that can be used to assign single blockades: the Ires\% values or the $\mathrm{L} 2$ fractional occupancy. We found that the residual current values of $\mathrm{HbA}$ were higher than $\mathrm{HbS}$, under all potentials and $\mathrm{pH}$ values tested (Fig. S5b, Table S2, S3 and S6), most likely reflecting the two additional charges of $\mathrm{HbA}$ compared to $\mathrm{HbS}$. More specifically, at $\mathrm{pH} 7.5$ and $+50 \mathrm{mV}$ the difference in Ires\% between $\mathrm{HbA}$ and $\mathrm{HbS}$ was maximised. Under these conditions, most blockades could be correctly assigned to either $\mathrm{HbA}$ or $\mathrm{HbS}$ using an Ires\% threshold value of $38.9 \%$ for L2. Analyzing 600 blockades using three nanopores, we found that $97.7 \pm 4 \%$ of single blockades collected from $\mathrm{HbA}$ events had an Ires\% higher than the threshold, while $97 \% \pm 1.3 \%$ of $\mathrm{HbS}$ events showed lower Ires\% values (Fig. S6). By 
contrast, the fractional level of $L 2$ occupancy was a less accurate predictor, as only $84.5 \pm 8.5 \%$ of $\mathrm{HbA}$ blockades showed higher fractional L2 occupancy compared to L1. These data indicate that PlyAB-E1 nanopore are remarkably sensitive to distinguish the single amino acid mutation in large folded proteins.

In infants, oxygen is carried by human foetal haemoglobin ( $\mathrm{HbF}, \alpha 2 \mathrm{\gamma} 2)$, which is a more efficient oxygen carrier than adult haemoglobin. Consequently, the early diagnosis of sickle cell anaemia in children is complex, as $\mathrm{HbF}$ compensates for the lower oxygen transport of $\mathrm{HbS}$. In fact, generating a high level of HbF in the patient's blood is advantageous during the treatment ${ }^{[46]}$. Hence, it is important to discriminate $\mathrm{HbF}$ from other variants for early sickle cell anaemia diagnosis and prognosis. $\mathrm{HbF}, \mathrm{HbA}$ and $\mathrm{HbS}$ contain two identical a chains, but different $\gamma$ - / $\beta$-chains (Fig. 3a), althoughthe two proteins have the same overall shape (Fig. $3 b)$. When $\mathrm{HbF}$ was added to the trans side of a PlyAB nanopore, two distinctive levels are observed as previously observed by $\mathrm{HbA}$ or $\mathrm{HbS}$. However, the blockade Ires\% was significantly higher (Ires\%-L1 = 42.5\% $\pm 1.1 \%$, Ires\%-L2 = 60.1\% $1.6 \%$ ) than either $\mathrm{HbA}$ or $\mathrm{HbS}$ (Fig. 3c). Therefore, PlyAB-E1 nanopores are capable of discriminating mixtures of all three haemoglobin variants, despite their small differences in amino acid sequence (Fig. $3 \mathrm{~d}$ ).

We further expand our work by showing that haemoglobin can be detected directly from disrupted red blood cells. Diluted sheep blood was disrupted using 0.02\% DDM and added to the chamber. After addition of haemoglobin, the current trace shows a combination of haemoglobin events and short-lived spikes (Fig 4a). Haemoglobin constitutes the majority of protein mass in red blood cells, explaining why the nanopore signal was not obscured by the presence of other proteins, especially when only long blockades ( $>0.5 \mathrm{~ms}$ ) were considered (Fig 4b). The ratio between the blocked level and open current level increases linearly with the concentration of haemoglobin from disrupted blood, showing that our nanopore system is capable of quantifying the haemoglobin concentration in blood (Fig 4c). 
\begin{tabular}{c|cccccc} 
& 5 & 15 & 25 & 35 & 45 & 55 \\
HbA & VHLTPEEEKSA & VTALWGKVNV & DEVGGEALGR & LLVVYPWTQR & FFESFGDLST & PDAVMMGNPKV
\end{tabular} HbF GHFTEEDKAT ITSLWGKVNV EDAGGETLGR LLVVYPWTQR FFDSFGNLSS ASAIMGNPKV

$\begin{array}{ccccccc} & 65 & 75 & 85 & 95 & 105 & 115 \\ \text { HbA } & \text { KAHGKKVLGA } & \text { FSDGLAHLDN } & \mathbf{8 5} & 95 & 105 & \end{array}$ HbF KAHGKKVLTS LGDAIKHLDD LKGTFAQLSE LHCDKLHVDP ENFKLLGNVL VTVLAIHFGK

$\begin{array}{llll}125 & 135 & 145\end{array}$

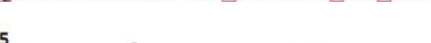

HbF EFTPEVQASW QKMVTGVASA LSSRYH
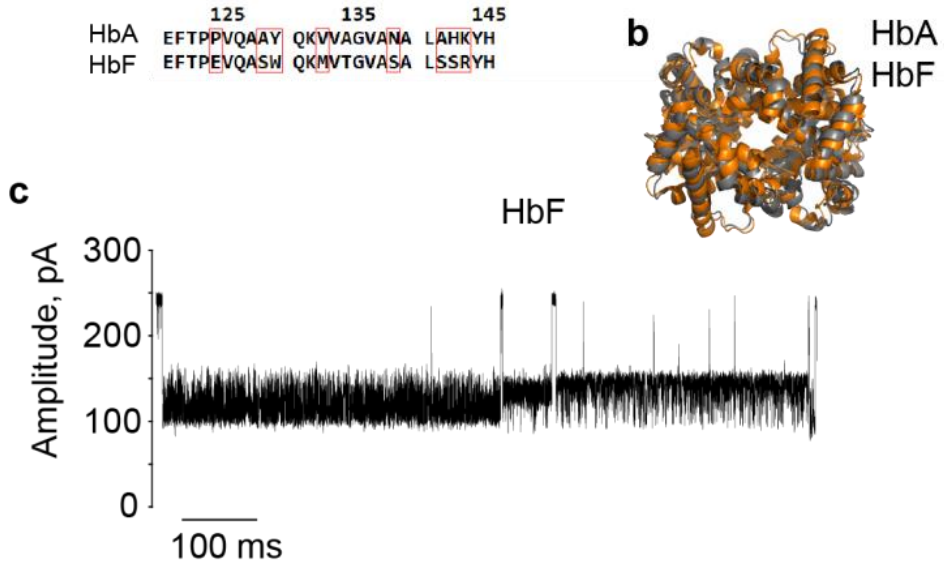

d

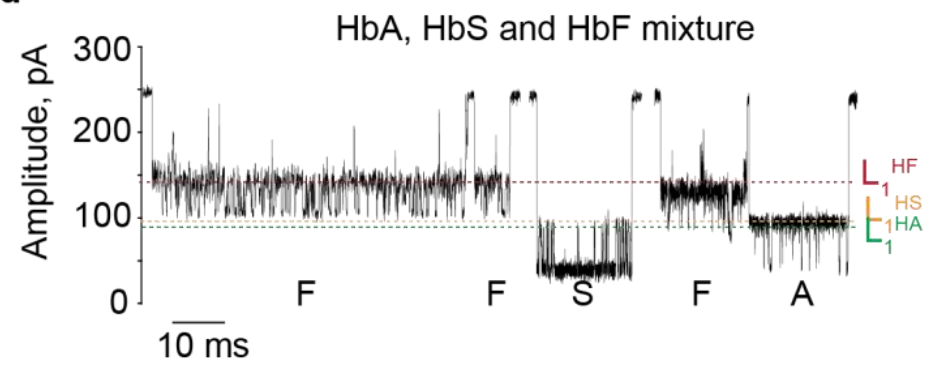

Figure 3. Discrimination of human fetal haemoglobin ( $\mathrm{HbF}$ ) from $\mathrm{HB} A$ and $\mathrm{HbS}$. (a) The sequence alignment of $\beta$ globin chain of $\mathrm{HbA}$ and $\gamma$ chain of $\mathrm{HbF}$. $\mathrm{HbF}(\alpha 2 \gamma 2)$ has two identical $\alpha$ subunits as $\mathrm{HbA}$. The alignment shows the difference between the $y$ chain of $\mathrm{HbF}$ and $\beta$ chain of $\mathrm{HbA}$. Residue differences are highlighted by red box. (b) Alignment between $\mathrm{HbA}$ (orange, PDB: 1 hgb) and $\mathrm{HbF}$ (gray, PDN: 4mqj). (c) Typical traces of $\mathrm{HbF}$ (trans) under +50 $\mathrm{mV}$. (d) Discrimination of mixture of $\mathrm{HbF}, \mathrm{HbA}$ and $\mathrm{HbS}$. The recordings were performed in $300 \mathrm{mM} \mathrm{NaCl}$ with a $50 \mathrm{KHz}$ sampling rate and $10 \mathrm{kHz}$ low-pass Bessel filter 
a

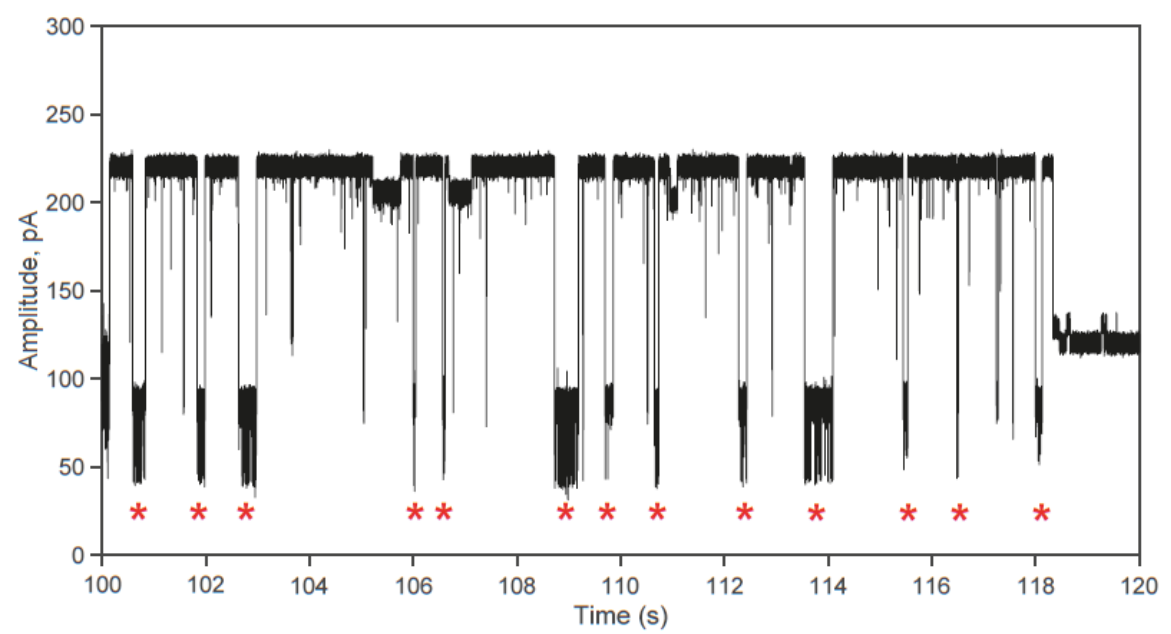

b
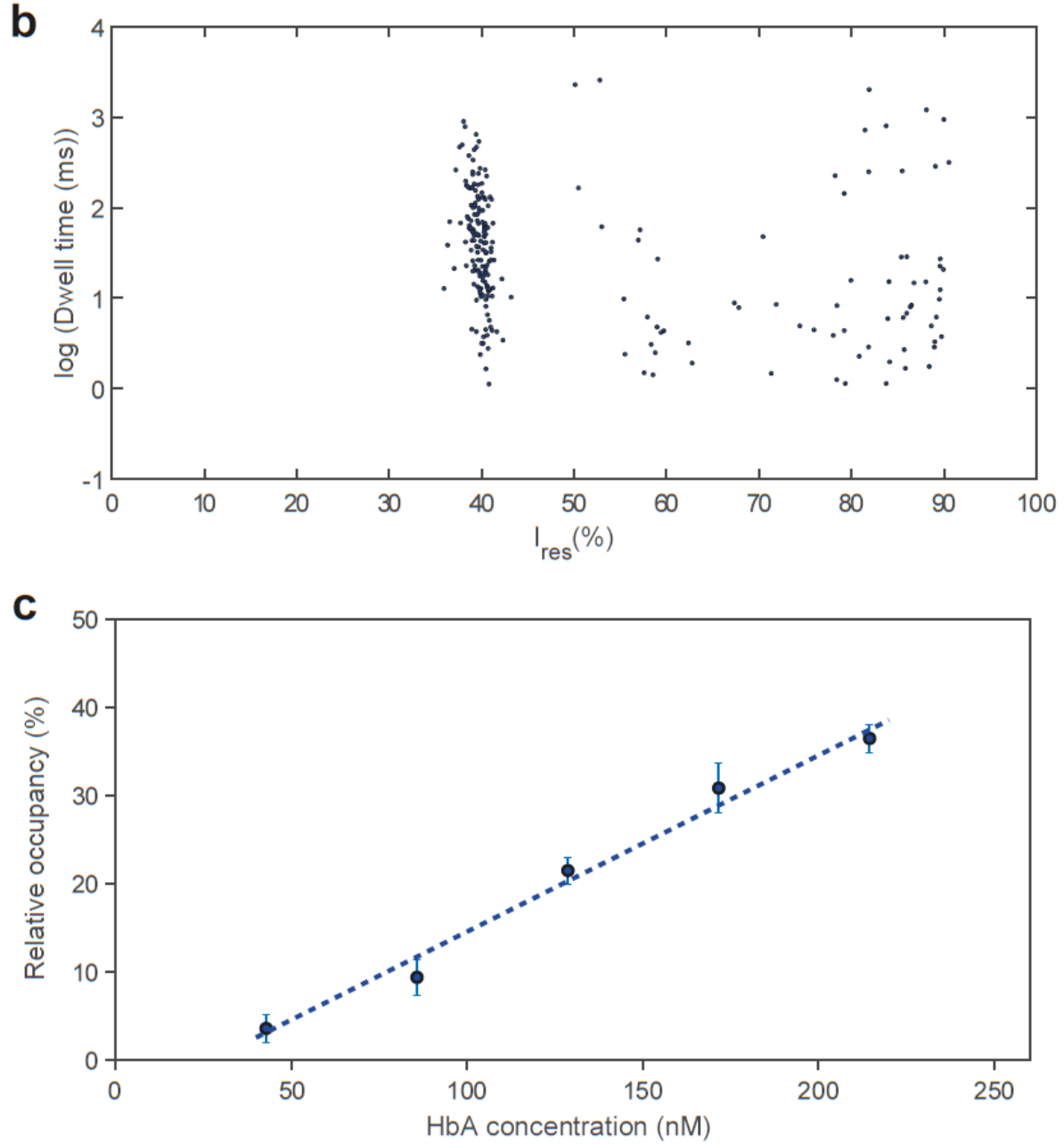

Figure 4. Discrimination of $\mathrm{Hb}$ from blood. a) Typical protein blockades from sampling sheep blood. Red blood cells were disrupted by adding 0.02\% DDM and then a 1:10,000 blood dilution (final) was sampled by PlyAB nanopores. Haemoglobin blockades are indicated by an asterix b) Ires(\%) vs dwell time plot for all events with a minimum dwell time of $0.5 \mathrm{~ms}$ after addition of $2 \mu \mathrm{L}$ disrupted blood to the chamber (1:10,000 final dilution). c) Relative occupancy of the $\mathrm{Hb}$ level with different $\mathrm{HbA}$ concentrations. $\mathrm{HbA}$ was isolated from sheep blood and quantified spectroscopically. The recordings were performed in $300 \mathrm{mM} \mathrm{NaCl}$ with a $50 \mathrm{KHz}$ sampling rate, a $10 \mathrm{kHz}$ low-pass Bessel filter and afterwards filtered using a $5 \mathrm{kHz}$ Gaussian filter. 
In conclusion, we employed PlyAB-E1 biological nanopores to count and differentiate human haemoglobin variants. Remarkably, despite the near identical shape and volume of the haemoglobin variants, ionic currents allowed identifying differences in haemoglobin proteins of one amino acid with more than $97 \%$ accuracy. In $\mathrm{HbS}$ a negatively charged residue substitutes a neutral residue. Thus, the different ionic signal possibly arose from the different electrophoretic force on both proteins, which most likely influenced their position inside the nanopore with respect of the constriction. Hence, as in isoelectric focusing techniques, nanopore currents are amenable of identifying single charge differences in individual proteins lodged inside the nanopore. In addition, we showed that the presence of other proteins did not obscure our measurements of haemoglobin, which concentration can be measured directly from disrupted blood without the need of purification steps.

Normal haemoglobin counts are 15 to $17 \mathrm{~g} / \mathrm{dL}$ (2.3-2.6 mM), concentrations that are easily accessible to nanopore analysis (here we measure $1 \mathrm{mg} / \mathrm{dL}$ or $150 \mathrm{nM}$ ). Hence, nanopores integrated into low-cost nanofluidic devices could be used for automated blood analysis in point-of-care devices. The exquisite detection discrimination of haemoglobin variants down to one amino acid would allow the counting and identification of $\mathrm{Hb}$ variants, with immediate application in the diagnosis of a variety of haemoglobin disfunctions such as those in sickle cell anaemia patients.

\section{Acknowledgments}

We thank the University of Groningen and ERC consolidator grant (726151, DeE-Nano) for funding G.H. and G.M.

\section{Conflict of interest}

The authors declare no conflict of interest.

\section{Keywords}

Biosensor, biological nanopore, PlyAB, haemoglobin, sickle cell anaemia 


\section{References}

[1] X. Yang, N. Z. Piety, S. M. Vignes, M. S. Benton, J. Kanter, S. S. Shevkoplyas, Clin. Chem. 2013, 59, 1506-1513.

[2] W. Guenter, G. Lawrence T, N Engl J Med 2005, 352, 1011-23.

[3] W. G. Zulstra, A. Buursma, Comp. Biochem. Physiol. -- Part B Biochem. 1987, 88, 251-255.

[4] P. Bhaskaram, N. Balakrishna, K. V. Radhakrishna, K. Krishnaswamy, Indian J. Pediatr. 2003, 70, 25-28.

[5] C. Weykamp, T. Penders, C. Siebelder, F. A. J. Muskiet, W. Slik, Clin. Chem. 1993, 39, 138-142.

[6] A. L.Louderback, E. Shanbrom., JAMA J. Am. Med. Assoc. 1967, 202, 158-159.

[7] R. M. Schmidt, S. Holland, Clin. Chem. 1974, 20, 591-594.

[8] W. J. Schnedl, T. Lahousen, S. J. Wallner, R. Krause, R. W. Lipp, Clin. Biochem. 2005, 38, 88-91.

[9] D. D. Mais, R. D. Gulbranson, D. F. Keren, Am. J. Clin. Pathol. 2009, 132, 34-38.

[10] J. Wang, Biosens. Bioelectron. 2006, 21, 1887-1892.

[11] P. Yager, G. J. Domingo, J. Gerdes, Annu. Rev. Biomed. Eng. 2008, 10, 107-144.

[12] S. Howorka, Z. Siwy, Chem. Soc. Rev. 2009, 38, 2360-2384.

[13] Y. L. Ying, Y. T. Long, J. Am. Chem. Soc. 2019, 141, 15720-15729.

[14] J. J. Kasianowicz, E. Brandin, D. Branton, David W. Deamer, Proc. Natl. Acad. Sci. 1996, 93, 13770-13773.

[15] G. Maglia, M. R. Restrepo, E. Mikhailova, H. Bayley, Proc. Natl. Acad. Sci. 2008, 105, 19720-19725.

[16] I. M. Derrington, T. Z. Butler, M. D. Collins, E. Manrao, M. Pavlenok, M. Niederweis, J. H. Gundlach, Proc Natl Acad Sci U S A 2010, 107, 16060-16065.

[17] D. Deamer, M. Akeson, D. Branton, Nat Biotech 2016, 34, 518-524.

[18] C. Dekker, Nat. Nanotechnol. 2007, 2, 209-215.

[19] B. N. Miles, A. P. Ivanov, K. A. Wilson, F. Doğan, D. Japrung, J. B. Edel, Chem. Soc. Rev. 2013, 42, 15-28.

[20] E. C. Yusko, B. R. Bruhn, O. M. Eggenberger, J. Houghtaling, R. C. Rollings, N. C. 
Walsh, S. Nandivada, M. Pindrus, A. R. Hall, D. Sept, J. Li, D. S. Kalonia, M. Mayer, Nat. Nanotechnol. 2017, DOI 10.1038/nnano.2016.267.

[21] J. Houghtaling, C. Ying, O. M. Eggenberger, A. Fennouri, S. Nandivada, M. Acharjee, J. Li, A. R. Hall, M. Mayer, ACS Nano 2019, 13, 5231-5242.

[22] I. Nir, D. Huttner, A. Meller, Biophys J 2015, 108, 2340-2349.

[23] R. Hu, J. V. Rodrigues, P. Waduge, H. Yamazaki, B. Cressiot, Y. Chishti, L. Makowski, D. Yu, E. Shakhnovich, Q. Zhao, M. Wanunu, ACS Nano 2018, DOI 10.1021/acsnano.8b00734.

[24] P. Waduge, R. Hu, P. Bandarkar, H. Yamazaki, B. Cressiot, Q. Zhao, P. C. Whitford, M. Wanunu, ACS Nano 2017, DOI 10.1021/acsnano.7b01212.

[25] L. Movileanu, S. Howorka, O. Braha, H. Bayley, Nat. Biotechnol. 2001, 18, 10911095.

[26] D. Rotem, L. Jayasinghe, M. Salichou, H. Bayley, J. Am. Chem. Soc. 2012, DOI 10.1021/ja2105653.

[27] S. Wang, F. Haque, P. G. Rychahou, B. M. Evers, P. Guo, ACS Nano 2013, 7, 98149822.

[28] M. A. Fahie, B. Yang, M. Mullis, M. A. Holden, M. Chen, Anal. Chem. 2015, 87, 11143-11149.

[29] M. Fahie, C. Chisholm, M. Chen, ACS Nano 2015, 9, 1089-1098.

[30] A. K. Thakur, L. Movileanu, Nat. Biotechnol. 2018, 37, 96.

[31] M. Soskine, A. Biesemans, B. Moeyaert, S. Cheley, H. Bayley, G. Maglia, Nano Lett. 2012, 12, 4895-4900.

[32] M. Soskine, A. Biesemans, M. De Maeyer, G. Maglia, J Am Chem Soc 2013, 135, 13456-13463.

[33] C. Wloka, N. L. Mutter, M. Soskine, G. Maglia, Angew. Chemie - Int. Ed. 2016, 55, 12494-12498.

[34] G. Huang, A. Voet, G. Maglia, Nat. Commun. 2019, 10, 835.

[35] G. Huang, K. Willems, M. Soskine, C. Wloka, G. Maglia, Nat Commun 2017, 8, 935.

[36] A. Biesemans, M. Soskine, G. Maglia, Nano Lett. 2015, 15, 6076-6081.

[37] M. Soskine, A. Biesemans, G. Maglia, J Am Chem Soc 2015, 137, 5793-5797.

[38] V. Van Meervelt, M. Soskine, S. Singh, G. K. Schuurman-Wolters, H. J. Wijma, B. 
Poolman, G. Maglia, J. Am. Chem. Soc. 2017, 139, 18640-18646.

[39] G. Huang, K. Willems, M. Soskine, C. Wloka, G. Maglia, Nat. Commun. 2017, 8, 113.

[40] N. S. Galenkamp, M. Soskine, J. Hermans, C. Wloka, G. Maglia, Nat. Commun. 2018, DOI 10.1038/s41467-018-06534-1.

[41] S. Zernia, N. J. van der Heide, N. S. Galenkamp, G. Gouridis, G. Maglia, ACS Nano 2020, 14, 2296-2307.

[42] C. Wloka, V. Van Meervelt, D. van Gelder, N. Danda, N. Jager, C. P. Williams, G. Maglia, ACS Nano 2017, 11, 4387-4394.

[43] N. Lukoyanova, S. C. Kondos, I. Farabella, R. H. P. Law, C. F. Reboul, T. T. CaradocDavies, B. A. Spicer, O. Kleifeld, D. A. K. Traore, S. M. Ekkel, I. Voskoboinik, J. A. Trapani, T. Hatfaludi, K. Oliver, E. M. Hotze, R. K. Tweten, J. C. Whisstock, M. Topf, H. R. Saibil, M. A. Dunstone, PLoS Biol. 2015, 13, 1-15.

[44] G. Huang, K. Willems, M. Bartelds, P. van Dorpe, M. Soskine, G. Maglia, Nano Lett. 2020, 20, 3819-3827.

[45] J. A. Koepke, L. Miller, Ann. Clin. Lab. Sci. 1972, 2, 335-342.

[46] I. Akinsheye, A. Alsultan, N. Solovieff, D. Ngo, C. T. Baldwin, P. Sebastiani, D. H. K. Chui, M. H. Steinberg, Blood 2011, 118, 19-27.

[47] R. Wei, V. Gatterdam, R. Wieneke, R. Tampé, U. Rant, Nat. Nanotechnol. 2012, 7, 257-263.

[48] J. Larkin, R. Y. Henley, M. Muthukumar, J. K. Rosenstein, M. Wanunu, Biophys. J. 2014, DOI 10.1016/j.bpj.2013.12.025. 


\section{Supplementary Information}

PlyAB nanopores detects single amino acid differences in folded haemoglobin variants

Gang Huang ${ }^{\dagger}$ and Giovanni Maglia ${ }^{\dagger, *}$

†Groningen Biomolecular Sciences \& Biotechnology Institute, University of Groningen, 9747 AG Groningen, The Netherlands

*Corresponding author:g.maglia@rug.nl 


\section{Table of Contents}

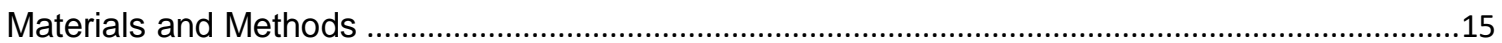

Pleurotolysin (PlyAB-E1) monomer expression and purification ..................................................15

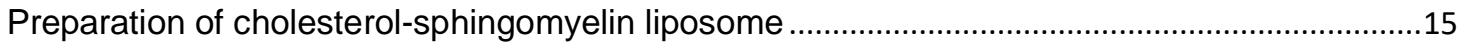

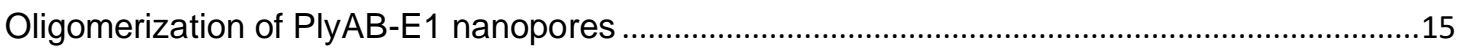

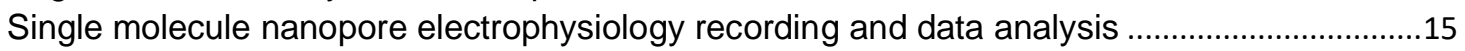

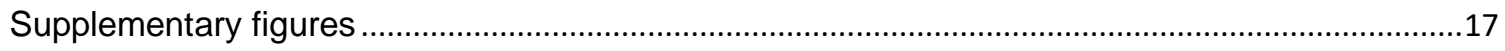

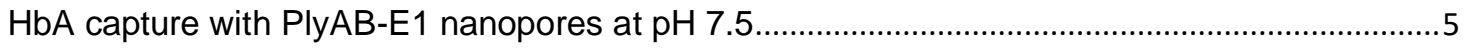

The voltage dependence of level 1 Ires $\%$ for $\mathrm{HbA}$ and $\mathrm{HbS}$ at $\mathrm{pH} 7.5$.....................................

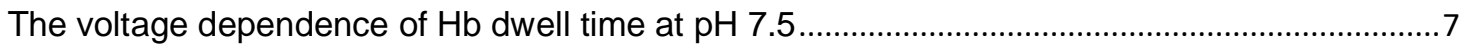

The dwell time of $\mathrm{Hb}$ in different $\mathrm{pH}$ conditions measured under $+50 \mathrm{mV}$..................................

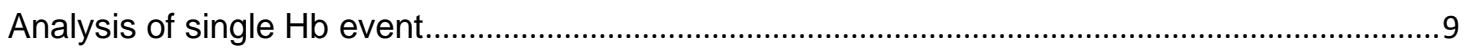

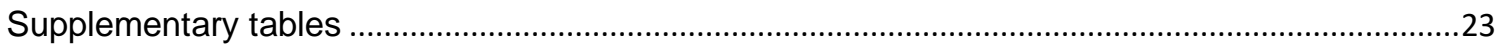

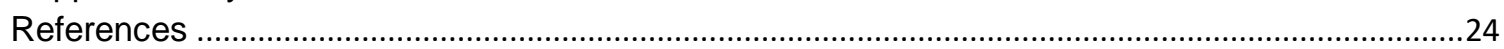




\section{Materials and Methods}

Sodium Chloride ( $\mathrm{NaCl}, \geqslant 99.5 \%$, \#7647-14-5) was purchased from Sigma-Aldrich. Tris hydrochloride ( $\geqslant 99 \%$, \#1185-53-1) and tris base ( $\geqslant 99.9 \%$, \#77-86-1) were purchased from ROTH. Sphingomyelin (Porcine brain, \# 860062) and 1,2Diphytanoyl-sn-glycero-3-phosphocholine (DPhPC, \#850356P) were obtained from Avanti Polar Lipids. Cholesterol ( $\geqslant 99 \%$, \#57-88-5), pentane ( $\geqslant 99 \%$, \#109-66-0) and hexadecane (99\%, 544-76-3) were bought from Sigma-Aldrich. Human HbA (\# 5465157-9) and HbS (\# H0392) were ordered from Sigma-Aldrich. Human fetal $\mathrm{Hb}$ (\# MBS702332) was purchased from MYBIOSOURCE. Difribinated sheep blood (\#10631715) was purchased from Thermo-Fisher. n-Dodecyl $\beta$-D-maltoside (DDM, \#D4641) was ordered from Sigma-Aldrich.

\section{Pleurotolysin (PlyAB-E1) monomer expression and purification}

PlyAB-E1 nanopore is an oligomeric protein composed by 26 pleurotolysin $A$ monomers and 13 pleurotolysin $B$ monomers. The pleurotolysin $A$ subunit in PlyAB$\mathrm{E} 1$ is a cysteine-free variant (PlyA-C62S-C94S, or PlyA-S) that was prepared to improve the nanopore stability in lipid bilayer. The pleurotolysin $B$ subunit is also cysteine-free and contains additional mutations (N26D, A328T, A464V, C441A, or PlyB-E1) that were introduced to improve the bilayer stability. Six-histidine tag were introduced in the C-terminus of both proteins for his-tag affinity purification. PlyA and PlyB were obtained and oligomerized as previously described. ${ }^{[1]}$ Protein monomers were kept at $4{ }^{\circ} \mathrm{C}$.

\section{Preparation of cholesterol-sphingomyelin liposome}

Cholesterol-sphingomyelin liposomes (1:1 mass ratio) were needed to trigger the oligomerization of two component pleurotolysin nanopores (PlyAB-E1). $25 \mathrm{mg}$ cholesterol and $25 \mathrm{mg}$ sphingomyelin were dissolved in $5 \mathrm{~mL}$ pentane by adding of $0.5 \% \mathrm{v} / \mathrm{v}$ ethanol. The lipid solvent was transferred to a round flask and lipid layer was created through the flask internal wall by slow rotation and heating using a hair-dryer. The round flask was then kept open at room temperature for 30 minutes for the complete evaporation of pentane. Then, $5 \mathrm{~mL}$ buffer $(150 \mathrm{mM} \mathrm{NaCl}, 15 \mathrm{mM}$ Tris, $\mathrm{pH}$ 7.5) was added to resuspend the lipid. The flask was placed in a sonication bath for 5 minutes to obtain the liposomes. Liposomes were $10 \mathrm{mg} / \mathrm{mL}$ in concentration and stored at $-20^{\circ} \mathrm{C}$.

\section{Oligomerization of PlyAB-E1 nanopores}

The oligomerization of PlyAB nanopore started with the incubation of PlyA monomers with cholesterol-sphingomyelin liposomes in a 1:10 mass at ambient temperature for 10 minutes. Then, the same amount of PlyB-E1 monomers was added into the lipoprotein mixture and kept for 2 hours at room temperature (liposome: PlyA : PlyB = $10: 1: 1, \mathrm{v} / \mathrm{v} / \mathrm{v})$. PlyAB-E1 lipoprotein were stored at $4{ }^{\circ} \mathrm{C}$ and $0.5 \mu \mathrm{L}$ of the lipoprotein were directly added to solution in chamber for getting pores in electrophysiology measurement.

\section{Single molecule nanopore electrophysiology recording and data analysis}

A chamber with two compartments (cis and trans) was utilized in the electrophysiology recordings. The two compartments were separated by a $25 \mu \mathrm{m}$-thick polytetrafluoroethylene film (Goodfellow Cambridge Limited) containing a 100 $\mu \mathrm{m}$ hole in the center. First, a drop $(\sim 10 \mu \mathrm{L})$ of $5 \% \mathrm{v} / \mathrm{v}$ hexadecane in pentane was loaded 
to the aperture in the polytetrafluoroethylene film and the chamber was kept at room temperature for 1 minute for the pentane to evaporate. Then $500 \mu \mathrm{L}$ of buffer was introduced into both compartments, and $10 \mu \mathrm{L}$ of $10 \mathrm{mg} / \mathrm{ml}$ 1,2-diphytanoyl-sn-glycero3-phosphocholine (DPhPC) in pentane was loaded into each chamber. The lipid bilayer was formed by pipetting the buffer from one side compartment. The potential was applied using $\mathrm{Ag} / \mathrm{AgCl}$ electrodes immersed in the two compartments and connected to a patch clamp amplifier (Axopatch 200B, Axon Instruments). The signal was digitized using a Digidata 1440 A/D converter (Axon Instruments). The ground electrode was connected to the cis compartment, the working electrode to trans side. Clampex 10.4 software (Molecular Devices) was employed for data collection and Clampfit (Molecular Devices) for data analysis. The dwell time, inter-event time, blockade level ( $\left.I_{B}\right)$ and open pore currents $\left(I_{0}\right)$ were determined by the "single channel search" function of Clampfit. The Ires $\%$ was calculate as $I_{B} / l_{\circ} \times 100 \%$, and was used throughout to characterize the blockade amplitude for each event. Average dwell time and inter-event times were calculated by fitting single exponentials to histograms of cumulative distribution of all events. The dwell times for the capture of $\mathrm{Hb}$ proteins were measured using the single channel search function in Clampfit (Molecular Devices) and ignoring the different current changes within the blockade (by ignoring events with a duration shorter than $0.5 \mathrm{~ms}$ ).

\section{Preparation of disrupted sheep blood}

$10 \mu \mathrm{L}$ of sheep blood was dissolved in $490 \mu \mathrm{L}$ buffer containing $150 \mathrm{mM} \mathrm{NaCl}$ and $15 \mathrm{mM}$ Tris buffered to $\mathrm{pH}$ 7.5. Afterwards, $0.02 \% \mathrm{n}$-Dodecyl $\beta$-D-maltoside (DDM) was added to disrupt the membranes of the red blood cells. The haemoglobin concentration in the disrupted blood was determined spectroscopically by measuring the absorbance at $540 \mathrm{~nm}$ and using the data compiled by Prahl. ${ }^{[3]}$ 


\section{Supplementary figures}

a

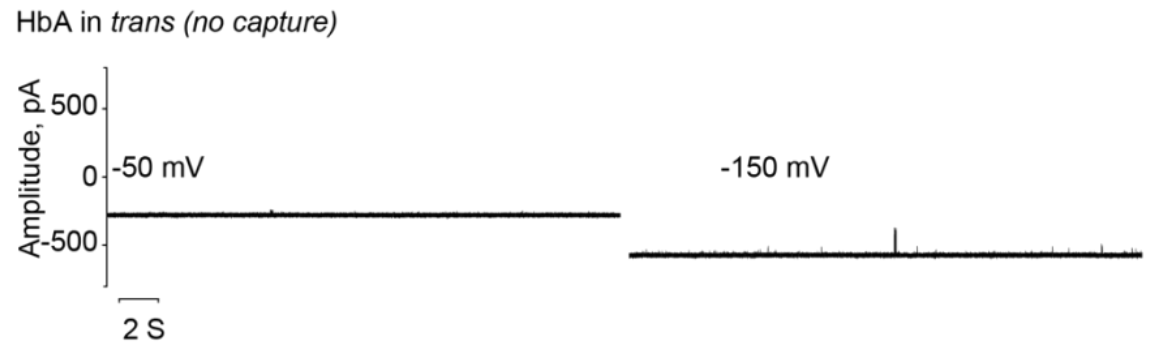

b

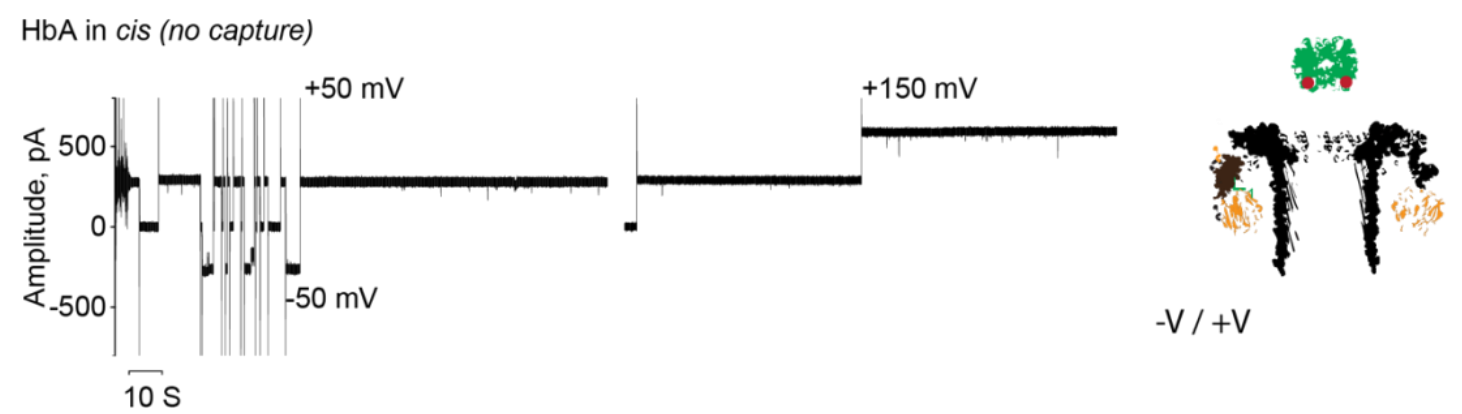

Figure Figure S1. Non-capturing condition of HbA with PlyAB-E1 nanopores. (a) When $\mathrm{HbA}$ (or other $\mathrm{Hb}$ proteins) was added into the trans side of PlyAB-E1 nanopores, $\mathrm{Hb}$ proteins could not be captured at negative potentials (up to $-150 \mathrm{mV}$ applied to trans), but could be captured at positive applied potentials (Figure 2, main text). (b) When $\mathrm{HbA}$ (or other Hb proteins) was added into the cis side of PlyAB-E1 nanopores, no current blockades were observed at either negative and positive potentials (+/- $150 \mathrm{mV}$, trans). HbA could not be captured from the cis side, probably due to the charge repulsion from the negative charge PlyAB constriction. HbA has an isoelectric point of $7.11^{[2]}$, hence it is slightly negatively charged at $\mathrm{pH} 7.5$. Recordings were collected in buffer with $300 \mathrm{mM} \mathrm{NaCl}, 15 \mathrm{mM}$ Tris and pH 7.5. 


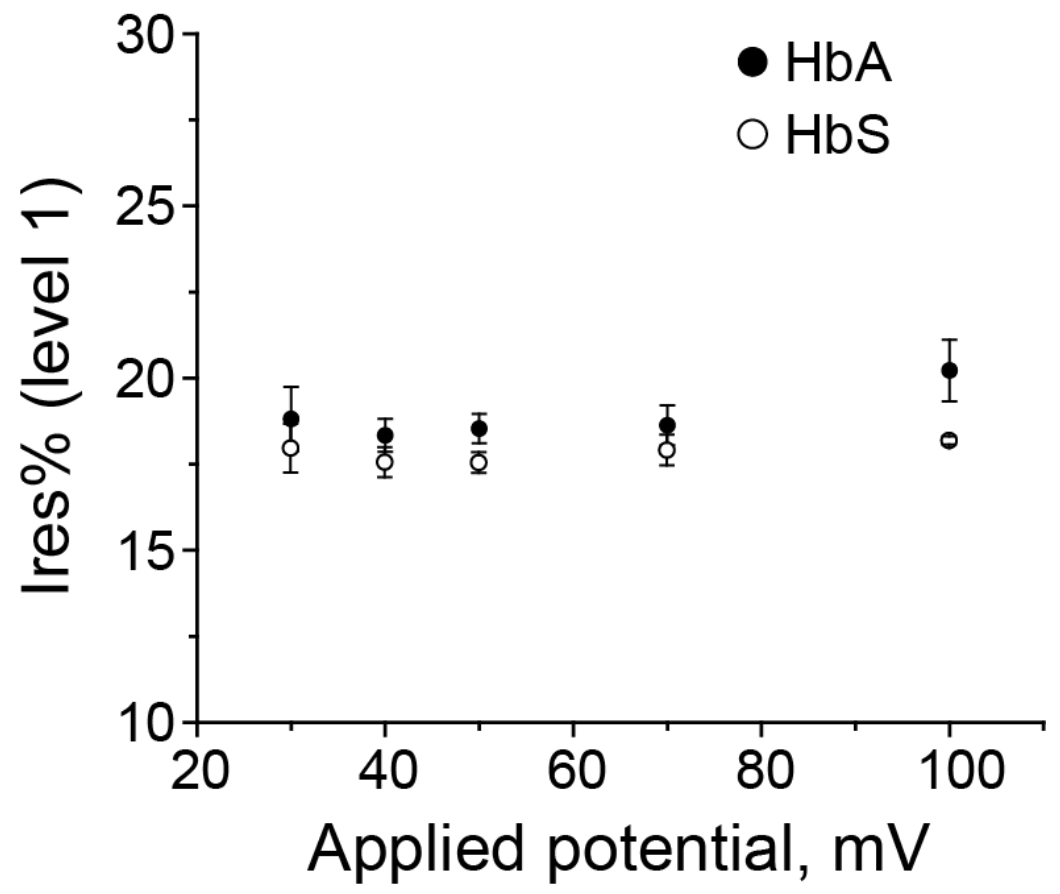

Figure S2. Voltage dependence of level 1 for $\mathrm{HbA}$ and $\mathrm{HbS}$ at $\mathrm{pH}$ 7.5. Error bars represented the standard deviation from three individual measurements. 


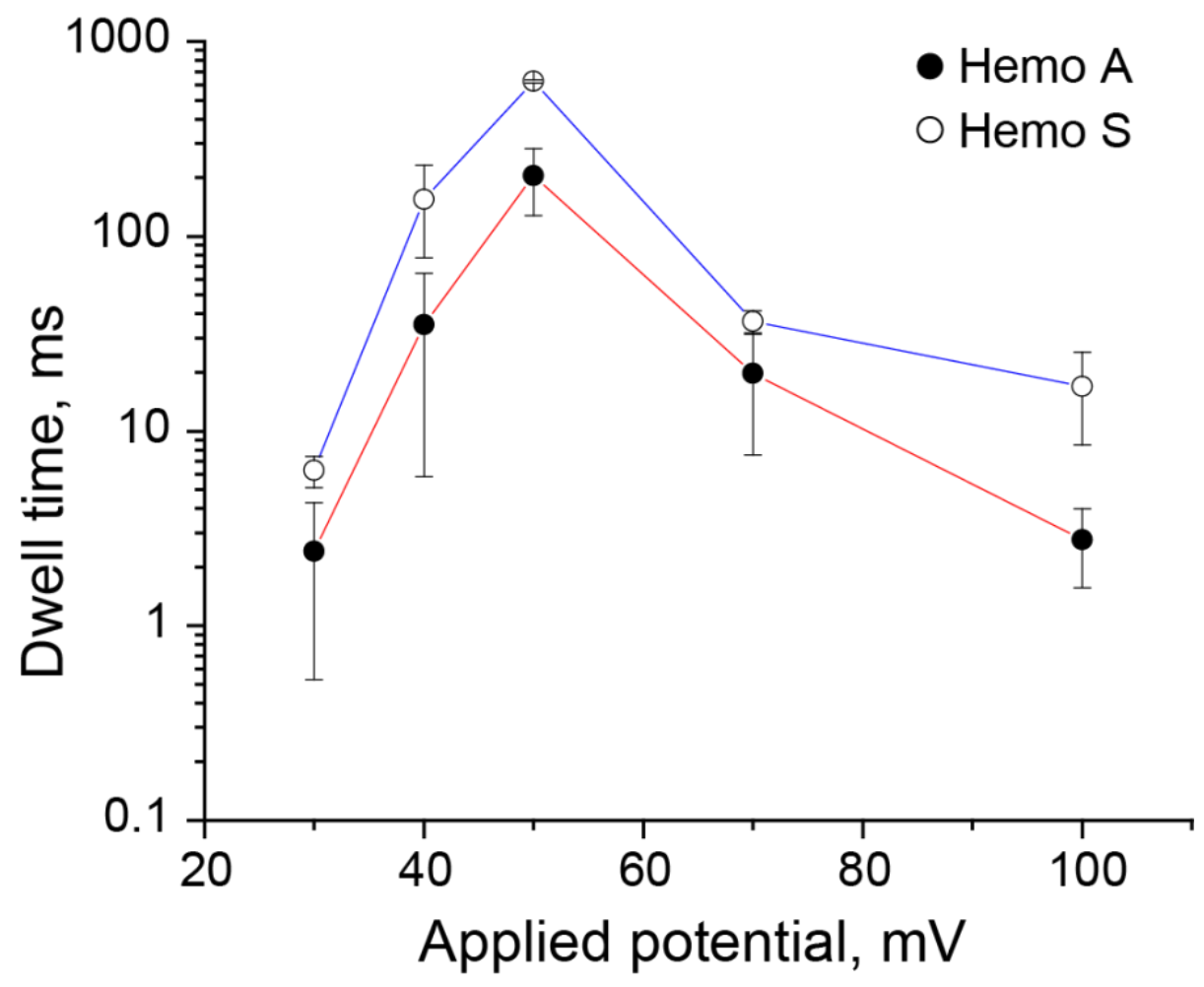

Figure S3. Voltage dependence of $\mathrm{Hb}$ residence times at $\mathrm{pH}$ 7.5. $\mathrm{HbA}$ and $\mathrm{S}$ were added to the trans side of PlyAB-E1. Error bars were standard deviations calculated with minimum 3 experiments. 


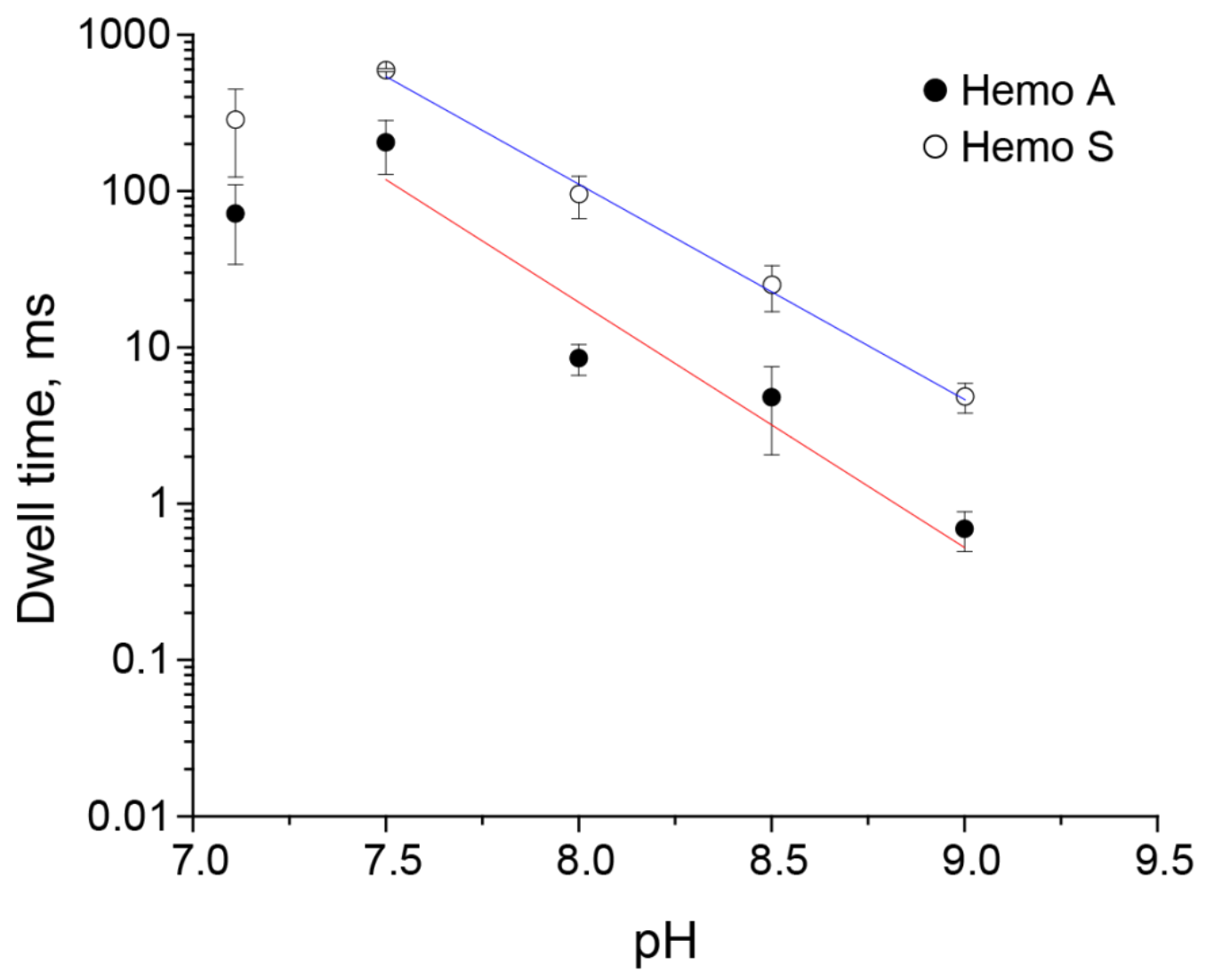

Figure S4. Dwell time of $\mathrm{Hb}$ under different $\mathrm{pH}$ conditions was measured under +50 $\mathrm{mV}$. $\mathrm{HbA}$ and $\mathrm{HbS}$ were added to the trans side of PlyAB-E1. Error bars were standard deviations calculated with minimum 3 experiments. 
a

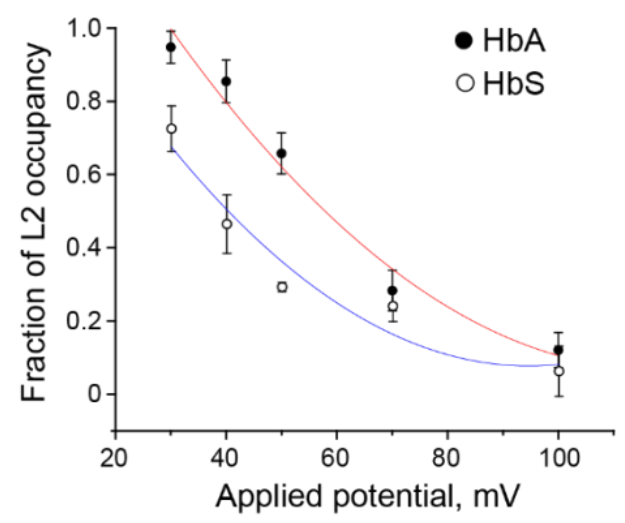

C

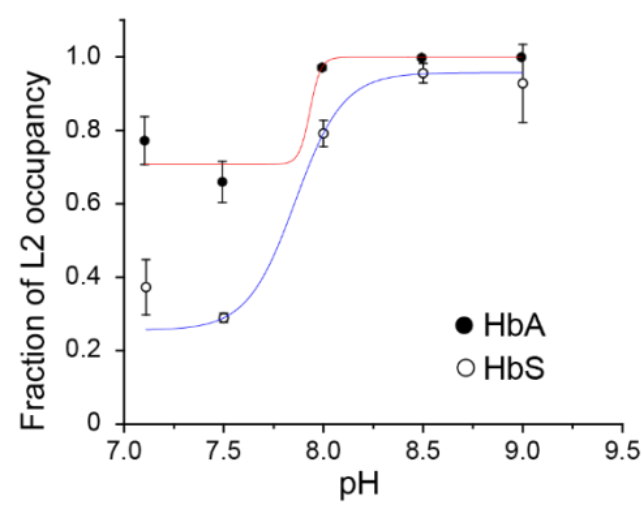

b

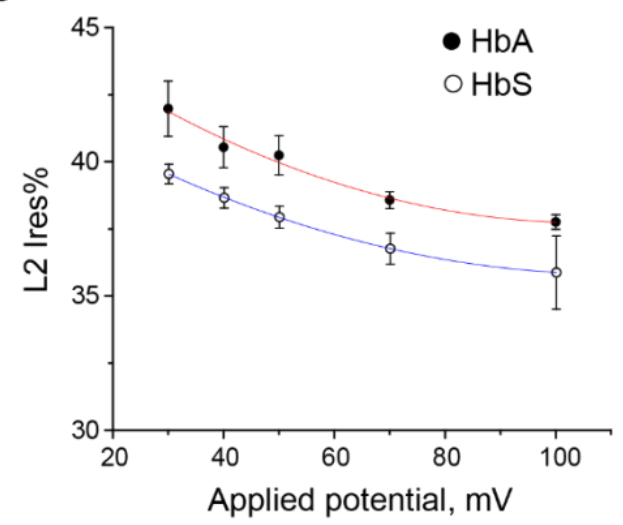

d

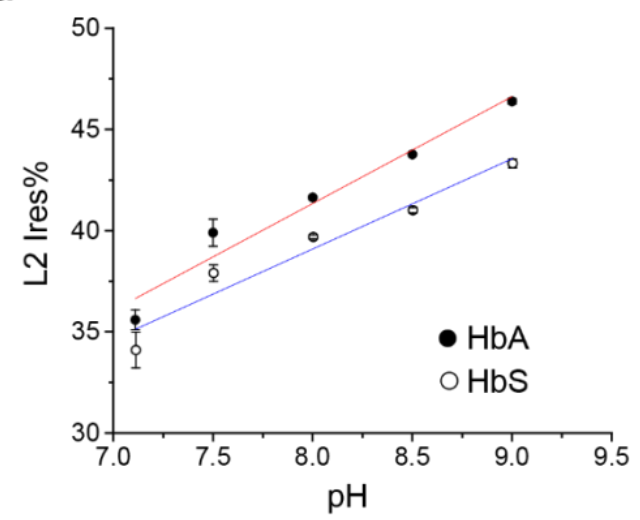

Figure S5. Haemoglobin detection at different voltages and $\mathrm{pH}$ values. (a) The voltage dependence of level 2 occupancy for $\mathrm{HbA}$ and $\mathrm{S}$ at $\mathrm{pH}$ 7.5. (b) The Ires\% of level 2 under difference voltages for $\mathrm{HbA}$ and $\mathrm{HbS}$ at $\mathrm{pH}$ 7.5. (c) Level 2 percentage of $\mathrm{HbA}$ and $\mathrm{HbS}$ when measured under different $\mathrm{pH}$ conditions under $+50 \mathrm{mV}$. (d) The level $2 \mathrm{Ires} \%$ of $\mathrm{HbA}$ and $\mathrm{HbS}$ was measured under different $\mathrm{pH}$ conditions and $+50 \mathrm{mV}$. The recordings were performed with PlyAB-E1 nanopores and in $300 \mathrm{mM}$ $\mathrm{NaCl}$ with a $50 \mathrm{KHz}$ sampling rate and $10 \mathrm{kHz}$ low-pass Bessel filter. 

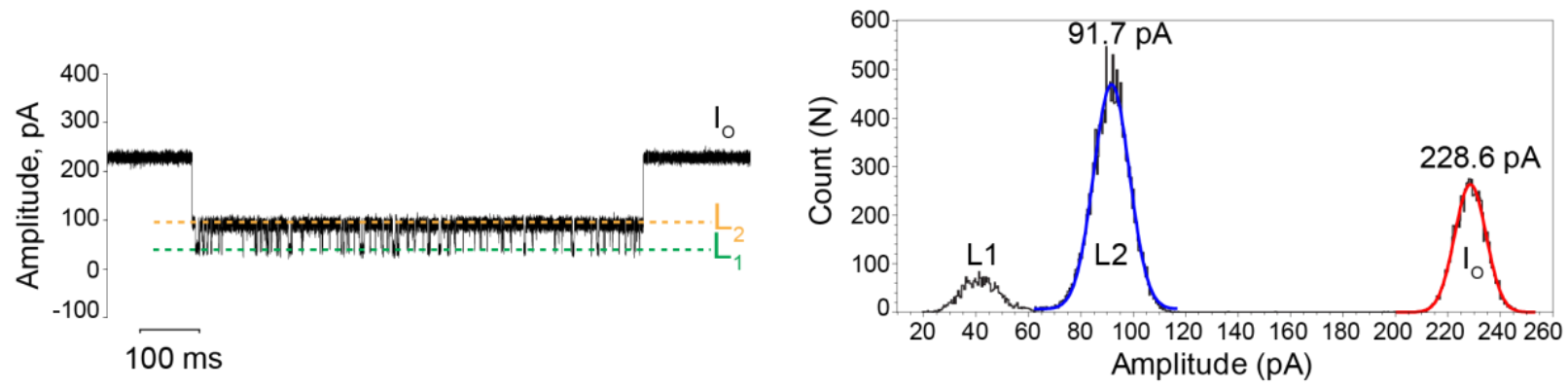

b

Conventional histogram of a single HbS event
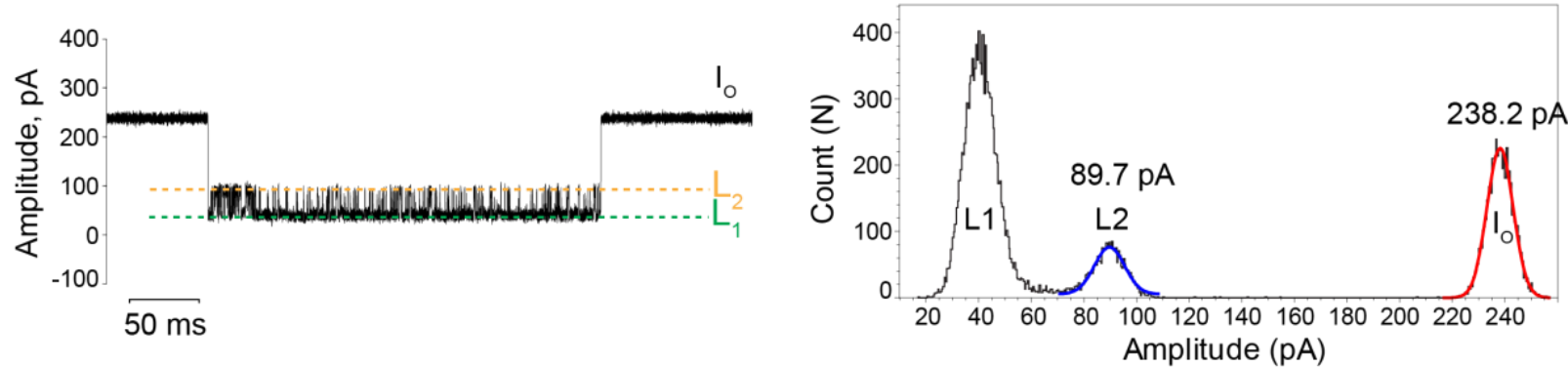

Figure S6. Example of analysis of single $\mathrm{HbA}$ and $\mathrm{HbS}$ events. Histograms were made from single events to generate the amplitude distribution of open pore level, level 1 and level 2. Gaussian fits were then used to obtain IB-L2, IB-L1 and lo. The Ires\% of the event was calculated by: IB-L2/lo*100\%. 600 single events were analyzed from 3 different measurements. 


\section{Supplementary tables}

Table S1. Voltage dependence of level 2 percentage for $\mathrm{HbA}$ and $\mathrm{HbS}$ at $\mathrm{pH} 7.5$

\begin{tabular}{ccccc}
$\begin{array}{c}\text { Voltage } \\
(\mathrm{mV})\end{array}$ & $\begin{array}{r}\mathrm{HbA} \\
\text { Percentage }\end{array}$ & S.D. & Percentage & S.D. \\
\hline+30 & 94.8 & 4.4 & 72.1 & 6.2 \\
+40 & 85.4 & 5.8 & 46.1 & 8 \\
+50 & 65.8 & 5.6 & 29 & 1.3 \\
+70 & 28.3 & 5.6 & 23.7 & 4.2 \\
+100 & 12.1 & 4.8 & 6.0 & 6.8 \\
\hline
\end{tabular}

Table S2. Ires\% of level 2 under difference voltages for $\mathrm{HbA}$ and $\mathrm{HbS}$ at $\mathrm{pH} 7.5$.

\begin{tabular}{ccccc}
\hline \multirow{2}{*}{ Voltages } & \multicolumn{2}{c}{$\mathrm{HbA}$} & \multicolumn{2}{c}{$\mathrm{HbS}$} \\
& Ires\% & S.D. & Ires\% & S.D. \\
\hline+30 & 42.0 & 1.0 & 39.5 & 0.4 \\
+40 & 40.5 & 0.8 & 38.6 & 0.4 \\
+50 & 40.2 & 0.7 & 37.9 & 0.4 \\
70 & 38.6 & 0.3 & 36.7 & 0.6 \\
+100 & 37.8 & 0.3 & 36.0 & 1.4 \\
\hline
\end{tabular}

Table S3. Ires\% of level 1 under difference voltages for $\mathrm{HbA}$ and $\mathrm{HbS}$ at $\mathrm{pH}$ 7.5.

\begin{tabular}{ccccc}
\hline \multirow{2}{*}{ Voltages } & \multicolumn{2}{c}{$\mathrm{HbA}$} & \multicolumn{2}{c}{ HbS } \\
& Ires\% & S.D. & Ires\% & S.D. \\
\hline+30 & 18.8 & 0.9 & 18.0 & 0.7 \\
+40 & 18.3 & 0.5 & 17.6 & 0.4 \\
+50 & 18.5 & 0.4 & 17.6 & 0.3 \\
+70 & 18.6 & 0.6 & 17.9 & 0.5 \\
+100 & 20.2 & 0.9 & 18.2 & 0.1 \\
\hline
\end{tabular}

Table S4. Voltage dependence of $\mathrm{HbA}$ and $\mathrm{HbS}$ residence times of at $\mathrm{pH}$ 7.5.

\begin{tabular}{ccccc}
\hline Voltages & $\begin{array}{c}\mathrm{HbA} \\
\text { Dwell time, } \\
\mathrm{ms}\end{array}$ & S.D. & $\begin{array}{c}\text { HbS } \\
\text { Dwell time, }\end{array}$ & S.D. \\
\hline+30 & 2.4 & 1.9 & 6.2 & 1.1 \\
+40 & 35.2 & 29.4 & 152.4 & 75.9 \\
+50 & 205 & 77.3 & 614.5 & 13.6 \\
+70 & 19.8 & 12.2 & 35.9 & 5.0 \\
+100 & 2.8 & 1.2 & 16.7 & 8.3 \\
\hline
\end{tabular}

Table S5. Level 2 percentage for $\mathrm{HbA}$ and $\mathrm{HbS}$ when measured a different $\mathrm{pH}$ under $+50 \mathrm{mV}$

\begin{tabular}{ccccc}
\hline \multirow{2}{*}{$\mathrm{pH}$} & $\mathrm{HbA}$ & \multicolumn{2}{c}{$\mathrm{HbS}$} \\
& Percentage & S.D. & Percentage & S.D. \\
\hline 7.11 & 77.0 & 6.6 & 37.3 & 7.5 \\
7.5 & 65.8 & 5.6 & 29.0 & 1.3 \\
8 & 96.9 & 0.7 & 79.2 & 3.6
\end{tabular}




\begin{tabular}{ccccc}
8.5 & 99.6 & 0.5 & 95.6 & 2.7 \\
9 & 99.8 & 0.1 & 92.8 & 10.6 \\
\hline
\end{tabular}

Table S6. Level 2 Ires $\%$ of $\mathrm{HbA}$ and $\mathrm{HbS}$ measured under $+50 \mathrm{mV}$ at different $\mathrm{pHs}$.

\begin{tabular}{ccccc}
\hline \multirow{2}{*}{$\mathrm{pH}$} & \multicolumn{2}{c}{$\mathrm{HbA}$} & \multicolumn{2}{c}{$\mathrm{HbS}$} \\
& Ires\% & S.D. & Ires\% & S.D. \\
\hline 7.11 & 35.6 & 0.5 & 34.1 & 0.9 \\
7.5 & 39.9 & 0.7 & 37.9 & 0.4 \\
8 & 41.6 & 0.1 & 39.7 & 0.1 \\
8.5 & 43.8 & 0.1 & 41.0 & 0.1 \\
9 & 46.4 & 0.1 & 43.3 & 0.2 \\
\hline
\end{tabular}

Table S7. Residence time of $\mathrm{HbA}$ and $\mathrm{HbS}$ events measured at different $\mathrm{pHs}$ under $+50 \mathrm{mV}$.

\begin{tabular}{ccccc}
\hline \multicolumn{3}{c}{$\mathrm{HbA}$} & \multicolumn{2}{c}{$\mathrm{HbS}$} \\
$\mathrm{pH}$ & $\begin{array}{c}\text { Dwell time, } \\
\mathrm{ms}\end{array}$ & S.D. & $\begin{array}{c}\text { Dwell time, } \\
\mathrm{ms}\end{array}$ & S.D. \\
\hline 7.11 & 71.8 & 37.8 & 296 & 168.5 \\
7.5 & 205 & 77.3 & 614.5 & 13.6 \\
8 & 8.5 & 1.9 & 98.8 & 29.9 \\
8.5 & 4.8 & 2.8 & 26.0 & 8.5 \\
9 & 0.7 & 0.2 & 5.0 & 1.1 \\
\hline
\end{tabular}

\section{References}

[1] G. Huang, K. Willems, M. Bartelds, P. van Dorpe, M. Soskine, G. Maglia, Nano Lett. 2020, 20, 3819-3827.

[2] J. A. Koepke, L. Miller, Ann. Clin. Lab. Sci. 1972, 2, 335-342.

[3] S. Prahl, "Optical Absorption of Hemoglobin", 1999,

http://omlc.ogi.edu/spectra/hemoglobin 